\title{
Road and environment
}

\author{
Gennady Akkerman ${ }^{1, *}$, Sergey Akkerman ${ }^{1}$, Alexey Kolos $^{2}$, and Nikolay Kapruschenko ${ }^{3}$ \\ ${ }^{1}$ Ural State Transport University, Kolmogorova st., 66, 620034 Ekaterinburg, Russia \\ ${ }^{2}$ Saint Petersburg State Transport University named after the Emperor Alexander I, Northwestern \\ Federal District, Moscow avenue, 9, 190031 Saint Petersburg, Russia \\ ${ }^{3}$ Sibir State Transport University, Dusi Kovalchuk st., 191, 630049 Novosibirsk, Russia
}

\begin{abstract}
A railway at all stages of its life cycle (design, construction, operation) interacts with the environment. The environment can be divided into two components, which, depending on the geographical location of the area and its economic development, are characterized by their regional factors. Natural: climate, relief, geology, hydrology, etc. Economic: the development of the area, the density of population and transport networks, industry, etc. The environment affects the choice of the main technical parameters of the railway, design characteristics, methods of construction and operation, and therefore, construction and operating costs. For the analysis of regional factors, a conditional parameter is adopted, the value of which changes in the same direction as the regional parameters. The regression equation between these parameters and the construction cost of 1 $\mathrm{km}$ of railway in the considered areas was revealed.
\end{abstract}

\section{Introduction}

When people combine two concepts: "road" and "environment", they very often mean "ecology". Indeed, any transport system is harmful for the environment: the main consumer of energy resources and an environmental polluter is road transport. Thus, on average, 150 watts-hour are spent for each t-km, railways - 30 watts-hours. In Russia, the polluting environment emissions from vehicles are approximately 22 million tons/year. Road transport accounts for $54 \%$ of pollution in the global balance. In different country this indicator varies from $13 \%$ to $80 \%$. With a mileage of $1 \mathrm{~km}$, a car burns up to $2 \mathrm{~kg}$ of air $(0.33 \mathrm{~kg}$ of oxygen), about 50 times more than the human needs. An aircraft consumes about 15 tons of fuel and 625 tons of air per 1 hour. Railway transport is the most economical in terms of energy costs. In addition to environmental pollution by emissions, vibration and acoustic pollution should be taken into account: a jet plane $-120 \mathrm{~dB}$, a highway up to $90 \mathrm{~dB}$, a train up to $75 \mathrm{~dB}$. Experiencing the impact of transport, the environment itself also affects it.

\section{Materials and methods}

The environment consists of two components:

\footnotetext{
${ }^{*}$ Corresponding author: GAkkerman@usurt.ru
} 
Economic: the development of the region, the density of the population and transport network, industry, agriculture, importance in the defense of the country, etc.

Natural: climate, weather, relief, geology, hydrology, flora and fauna, etc.

The environment affects the design characteristics, the choice of parameters, the methods of construction and operation of the transport system and, ultimately, the construction and maintenance costs of the future road. The cost indicators are influenced by such characteristics of the region as the availability of communication routes, population density.

Let us name the parameters that depend on the geographic location of the region and its "economic" development by regional factors.

Regional factors ultimately affect the cost indicators of the road at all phases of its life cycle.

- at the design stage: on the choice of technical parameters of the road, on which, in turn, the cost of construction and operation of the road depends;

- at the construction stage: increase in the cost of production of works, especially in harsh climatic conditions $[1,2,3]$;

- at the operation stage: increase in the cost of costs that depend on and are independent of the movement of trains [4].

However, the costs for the accepted parameters of the line depend not only on regional factors, but also on the length of the road, which is determined by the coefficient of development $\lambda$ for railways, for highways - the coefficient of elongation. Length of the road

$$
L=\lambda l_{0},
$$

wherel0 - the length of the geodetic line in $\mathrm{km}$.

Long-term experience shows that for railways in flat terrain $\lambda=1.1$; in hilly terrain $\lambda \leq 1,2$; in mountainous terrain $\lambda \leq 1.4$, sometimes even more $[6,7]$. It should be noted that the coefficient of development itself depends, in addition to regional factors, on the category (class) of the road and on the length of the road, see Fig. 1.

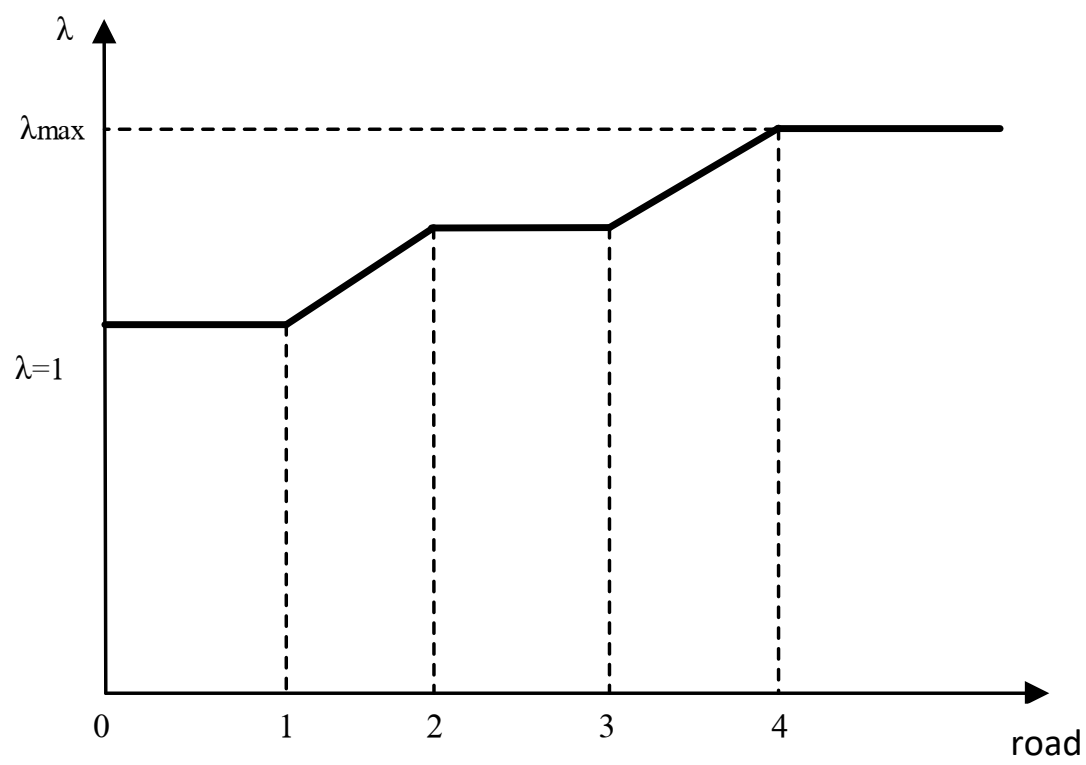

Fig. 1. Dependence of $\lambda$ on the length of the road.

1. Section $0-1$ is so small that there are no "obstacles" on it $\lambda=1$; 
2. Section 1-2 - local "obstacles" appear and the development coefficient begins to grow;

3. Section 2-3 - the number of local "obstacles" on average is constant per unit of road length and $\lambda=$ const;

4. Section 3-4 - the lengthening of the road is due to "obstacles" requiring a change in the direction of the route. Coefficient $\lambda$ is growing.

On the section after the number 4 , the interval $\lambda=\lambda_{\max }$ - the length of the road has increased so much that the number of all obstacles per unit length is constant. The length of the section $0-4$ is on average $60 \div 70 \mathrm{~km}$.

To analyze the influence of regional factors, we bring them to the conditional parameter $\tau$, the value of which changes in the same direction as the regional factors. For example, when they are deteriorating, the parameter $\tau$ is growing. For this parameter, we take the time during which all precipitation that fell during the year in a layer $\mathrm{h} \mathrm{mm}$ evaporates from the conditional area $\mathrm{S}$ at the evaporation rate $\mathrm{V}$, the average annual air temperature $\mathrm{t}^{\circ} \mathrm{C}$ and relative humidity $\mathrm{W}[7,8]$.

Time of evaporation:

$$
\tau=\frac{h * S}{V}
$$

The conditional area S takes into account such natural formations as swamps, forests, etc., depends on the development of the area (population density, transport network).

$$
S=(1-\gamma C-\beta H)(1+J)(1+D)(1+M)(1+T) \alpha_{1} \alpha_{2} \alpha_{3} \alpha_{4}
$$

Here: $\gamma$ - conditional width of the land allotment lane along the road [9];

$\mathrm{N}$ - density of the transport network, $\mathrm{km} / \mathrm{m}^{2}$;

$\beta$ - share of the developed territory per 1 person;

$\mathrm{P}$ - population density;

$\alpha, \beta$ actual weighting factors showing the significance of the considered factors.

$\mathrm{F}, \mathrm{S}, \mathrm{C}, \mathrm{T}$ - accordingly the shares of forests, swamps, congelation and tundra.

The deterioration of each of the factors under consideration (the development of the region, a decrease in temperature) is $\tau$ growing, and vice versa; see Table 1.

Table 1 is calculated under $\alpha=1 ; \lambda=1 ; \beta=3104$ км2чел; $\gamma=0,1$ км.

Table 1. Parameter $\tau$ for some regions

\begin{tabular}{|c|c|c|c|c|c|}
\hline Region & $\begin{array}{c}\text { Ryazan } \\
\text { region }\end{array}$ & Omsk region & $\begin{array}{c}\text { South of the } \\
\text { Krasnoyarsk } \\
\text { Krai }\end{array}$ & $\begin{array}{c}\text { Tyumen } \\
\text { region }\end{array}$ & $\begin{array}{c}\text { Komi } \\
\text { Republic }\end{array}$ \\
\hline$\tau$ & 0.315 & 0.358 & 0.656 & 0.966 & 1.320 \\
\hline
\end{tabular}

A systematic analysis showed $[10,11,12,16]$, that there is a correlation between $\tau$ and the estimated cost of $1 \mathrm{~km}$ of a number of railways. The correlation coefficient between $\tau$ and the cost of $1 \mathrm{~km}$ is 0.6 .

Regression equation looks like:

$$
C_{1 \kappa M}=\lambda(97,8+124,5 \tau) d,{ }^{\text {mblc.pyб. }} /{ }_{1 \kappa M}
$$

$\lambda$ - line development coefficient;

$d$ - coefficient of transition to modern prices. Can be accepted as $d \approx 80 \div 100$.

It should be noted that $\tau$ is not the only feature of the region, it is likely that you can choose others that meet the characteristics of the area. 
Line development coefficient, in addition to the mentioned conditions, depends on the heterogeneity of the territory. The heterogeneity of the territory can be manifested by different hydrological and engineering-geological conditions, different waterlogging, the presence of lakes, the presence of permafrost soils, sharply different relief forms, etc.

For the first time, the need to assess the heterogeneity of the territory was faced with the computer solution of the problem of transport development of oil and gas fields in the northern regions of Western Siberia [13, 14, 15].

Let us name the areas in which the aforementioned parameters are the same by their natural-territorial complexes.

The initial materials for the isolation of such complexes were:

- topographic and engineering-geological maps Scale 1:25,000;

- photographic plan, aerial photographs;

- materials of previous research.

The outlines of the boundaries of the complexes were also influenced by the possibility of using a rational design of the roadbed and artificial structures within each of the considered areas. In addition, the volumes and methods of work were taken into account and specific cost indicators were determined (the cost of $1 \mathrm{~km}$ of road).

Cost indicators, as a rule, were determined by the total costs. But this method is laborious and at the stage of feasibility study is not always provided with initial information. Therefore, in some cases, cost indicators were taken in the same way with similar objects.

The road route was laid according to the "cost model" shown on the cartographic material (map, photographic plan, etc.) by arrays of unit values, the location of which coincides with the natural-territorial complex or with the cells of the digital terrain model.

Let us call an area that is not included in the unit cost area a background.

Then it is possible that:

- construction within the background is more rational than in natural-territorial complexes scattered within it, and creating heterogeneity of the territory. For example, swamps, lakes, separated by areas with soils suitable for construction;

- construction within the background is less favorable than in areas that create heterogeneity. For example, a swampy area with "islands" of soils suitable for construction.

The criterion for assessing the heterogeneity of the territory can be such a concept as entropy, H [14]:

$$
\mathrm{H}=\mathrm{H}_{1}+\mathrm{H}_{2}
$$

Here, $\mathrm{H}_{1}$ - the entropy, which is determined by the heterogeneity (uncertainty) of the "cost" relief.

$\mathrm{H}_{2}$ - entropy as a quantitative parameter of the unevenness of the location of naturalterritorial complexes in the territory under consideration:

$$
H_{1}=-\sum_{j=1}^{j=n} \frac{s_{j} C_{j}}{\sum_{j=1}^{j=n} s_{j} C_{j}} * \log _{2} \frac{s_{j} C_{j}}{\sum_{j=1}^{j=n} s_{j} C_{j}}
$$

Here $S_{j}$ - area of the region (natural-territorial complex);

$\mathrm{C}_{\mathrm{j}}$ - unit cost of construction in the $\mathrm{j}_{\text {th }}$ region;

$\mathrm{n}$ - number of natural-territorial complexes.

If we impose a grid with a step $\Delta \mathrm{X}$ and $\Delta \mathrm{Y}$ on the tracing area (the $\mathrm{X}$ axis coincides with the geodetic line, and the $\mathrm{Y}$ axis is perpendicular to it), then the entropy of the distribution of the centers of natural-territorial complexes over the area is represented as the sum of the entropies of the distribution of the centers of these complexes along the $\mathrm{X}$ and $\mathrm{Y}$ axes.

$$
\mathrm{H}_{2}=\mathrm{H}_{\mathrm{x}}+\mathrm{H}_{\mathrm{y}}
$$


Then $\mathrm{H}_{2}$ is defined as

$$
H_{2}=-\left(\sum_{j=1}^{n} \frac{m_{i}}{n} \log _{2} \frac{m_{i}}{n}+\sum_{j=1}^{n} \frac{r_{k}}{n} \log _{2} \frac{r_{k}}{n}\right.
$$

$m_{i}$ and $r_{k}$ - the number of "hits" of the centers of natural-territorial complexes in the interval, respectively, $\Delta \mathrm{X}$ and $\Delta \mathrm{Y}$.

The fundamental change in $\lambda$ from entropy, which characterizes the heterogeneity of the territory, see Fig. 2.

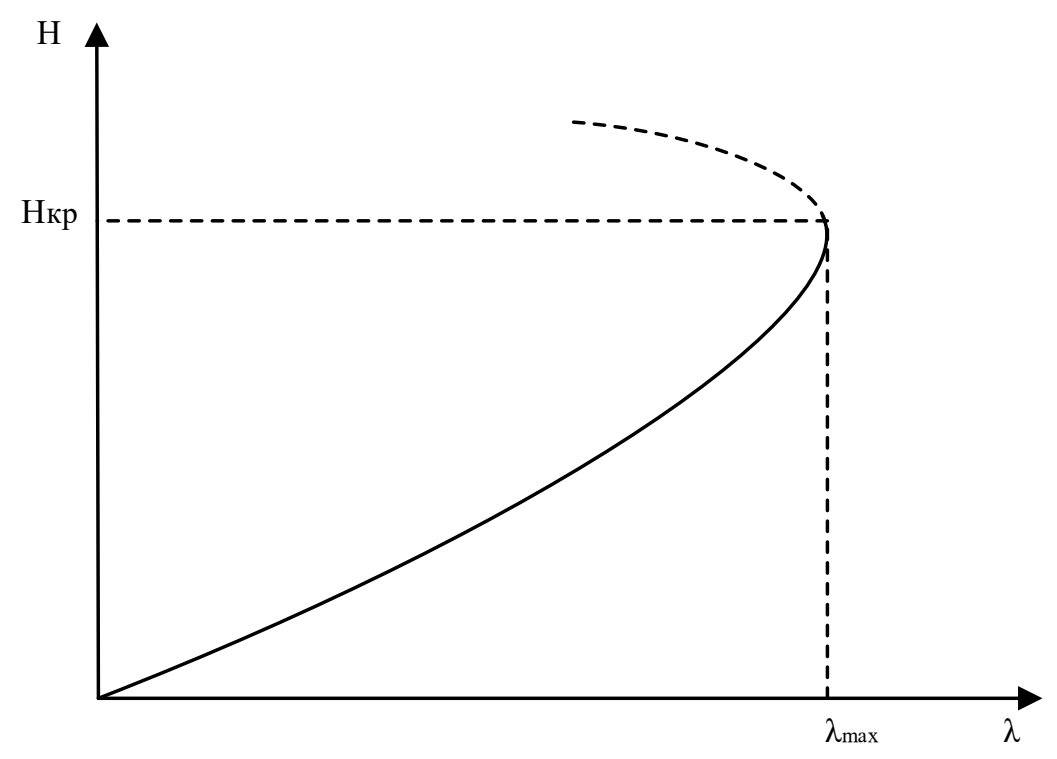

Fig. 2. $\lambda=\mathrm{f}(\mathrm{H})$

For the case when the background is more favorable for construction, $\lambda$ increases to the maximum value, with a further increase in entropy, as a criterion for the heterogeneity of the territory, the lengthening of the route does not necessarily lead to a decrease in construction costs - the development coefficient may decrease.

\section{Results and discussion}

According to the considered road designs, the entropy characterizing the heterogeneity of the terrain in the regions of Western Siberia varied within $2.5 \div 3.8$. With an increase in entropy, this leads to the appearance of a larger number of competitive route options, which means an increase in the complexity and cost of design.

Due to the increase in regional factors, the cost of building $1 \mathrm{~km}$ of railways also increases. So, according to equation (4), for the considered areas, this cost increases by more than 2 times.

The results obtained do not contradict, and in some cases, coincide with the results of the analysis of road projects in the regions under consideration.

\section{Conclusions}

The road has on the natural environment quite often a negative impact by its pollution and always a change in the relief. 
The impact of the natural and, in part, the economic environment on the road affects:

- change of its technical and technological parameters laid down in the project;

- the increase in the cost of construction due to the severity of the region according to the results of the considered regions by 4 or more times;

- an increase in the coefficient of development (line length) due to the heterogeneity of the territory;

- if the territory is homogeneous, then the entropy of such a territory is zero, regardless of the fact that the background is favorable or not favorable for the construction of a road.

\section{References}

1. V.D. Shapiro, Design Management, 610 (1996)

2. A.A. Burnashev, N.S. Nikerov, Taking into account the influence of climatic factors in the design and construction of mainline railways, 22 (1989)

3. B.M. Davidson, Meteorology and Hydrology, 7, 47 (1973)

4. A.A. Romanov, Scientific problems of construction of the BAM.: Collection of scientific works, Novosibirsk, 73 (1975)

5. G.L. Akkerman, S.G. Akkerman, Design of a new railway line, 35 (2017)

6. I.V. Turbin, Survey and design of railways, 480 (1989)

7. L.T. Matveyev, Fundamentals of general meteorology, 301 (1965)

8. A.M. Baranov, Aviation meteorology, 383 (1981)

9. S.G. Akkerman, Organization of the right-of-way as part of the transport infrastructure, 154 (2003)

10. E.I. Ventsel, Probability theory, 576 (1974)

11. V.M. Ivanov, V.N. Kalinina, Mathematical statistics, 368 (1981)

12. A.K. Metropolsky, Statistical computing techniques, 576 (1971)

13. G.L. Akkerman, G.D. Mikhailov, Consideration of engineering-geological and hydrological heterogeneity of the territory during automated tracing of roads on a computer in flat terrain, 60, 90 (1979)

14. G.L. Akkerman, Uncertainty in the design of railways, 74, 80 (1985)

15. Gennady Akkerman, Sergei Akkerman, Aleksandr Mironov, MATEC Web of Conferences, 02017 (2018)

16. Gennady Akkerman, Sergei Akkerman, Boris Sergeev, Advances in Intelligent Systems and Computing, 1116, 720 (2020) 